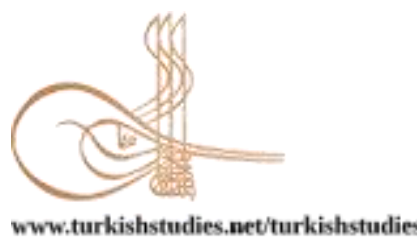

Turkish Studies

www.turkishstudies.netturkishstudies

eISSN: $1308-2140$

BALAKAN

Sponsered by IBU

Research Article / Araștırma Makalesi

\title{
Ağırlıklı Squat Sıçrama Hareketi Esnasındaki Hız Değerlerinin Analizi: Anaerobik Güç ve Maksimal Kuvvet Önemli Bir Faktör Mü?*
}

\author{
The Analysis of Velocity Values During Loaded-Squat Jump Movement: Are Anaerobic Power and \\ Maximal Strength an Important Factor?
}

\author{
İbrahim Can $^{* *}$ - Serdar Bayrakdaroğlü ${ }^{* * *}$ - Nuri Topsakal ${ }^{* * * *}$
}

\begin{abstract}
The aim of this study is to determine whether the anaerobic power and maximal strength are an important factor for velocity values during loaded-squat jump movement. For this purpose, 36 male students (age: 21,4 \pm 1,57 years; height: 175,2 $\pm 5,91 \mathrm{~cm}$; weight: $68,7 \pm 7,12 \mathrm{~kg}$ ) who are studying at school of physical education and sport at the Gumushane University and have active athlete license in different sport branches participated in the study voluntarily. In the study, loaded-squat jump ( $\mathrm{SJ}_{\text {Loaded }}$ ) movement was practiced by using an external load equaled to $40 \%$ of their body weights in order to determine velocity parameters of the participants. Also, in order to determine the maximal dynamic strength of the participants, one repetition maximal strength $(1 \mathrm{RM})$ in the full back squat $\left(\mathrm{SQ}_{\text {Full }}\right)$ movement and anaerobic power tests were done. For the analysis of data, Shapiro-Wilk normality test, descriptive statistics and Pearson Correlation analysis were used. According to the analysis results, there is a positive and statistically significant relationship between the absolute and relative 1RM strength values in the $S Q_{\text {Full }}$ movement and mean relative anaerobic power values together with peak velocity values obtained in the concentric phase of $\mathrm{SJ}_{\text {Loaded }}$ movement of participants. Also, it was found that there is a positive and statistically significant relationship between 1RM squat strength and both absolute maximal anaerobic power and absolute mean anaerobic power values. There was no statistically significant relationship was found except for this. As a result, since there is a significant relationship between strength and velocity values in terms of absolute and relative, it can be asserted that as the strength increases,
\end{abstract}

\footnotetext{
* Bu çalışma, 02-06 Ekim 2019 tarihinde Ankara'da düzenlenen "5th International Eurasian Congress on Natural Nutrition, Healthy Life \& Sport' Kongresinde sözel sunum olarak sunulmuştur.

** Doç. Dr., Iğdır Üniversitesi, Beden Eğitimi ve Spor Yüksekokulu, Antrenörlük Eğitimi Bölümü

Assoc. Prof. Ĭgdır University, School of Physical Education and Sport, Department of Coaching Education

ORCID 0000-0002-2050-1473

ibrahimcan_61_@hotmail.com

**** Dr. Öğr. Üyesi, Gümüşhane Üniversitesi, Beden Eğitimi ve Spor Yüksekokulu, Antrenörlük Eğitimi Bölümü Assist. Prof. Gümüşhane University, School of Physical Education and Sport, Department of Coaching Education ORCID 0000-0002-2166-6675

bayrakdaroglu85@gmail.com

***** Dr. Öğr. Üyesi, Düzce Üniversitesi, Spor Bilimleri Fakültesi, Antrenörlük Eğitimi Bölümü

Assist. Prof. Düzce University, Faculty of Sport Sciences, Department of Coaching Education

ORCID 0000-0003-1583-107X

topsakal.nuri@gmail.com

Cite as/ Atıf: Can, İ., Bayrakdaroğlu, S., Topsakal, N. (2020). Ağırlıklı squat sıçrama hareketi esnasındaki hız değerlerinin analizi: anaerobik güç ve maksimal kuvvet önemli bir faktör mü?. Turkish Studies, 15(3), 1709-1719. https://dx.doi.org/10.29228/TurkishStudies.42683

Received/Geliş: 28 March/Mart 2020

Accepted/Kabul: 20 June/Haziran 2020

Checked by plagiarism software

Copyright $\odot$ MDE, Turkey

Published/Yayın: 25 June/Haziran 2020

CC BY-NC 4.0
} 
there will be an increase in peak velocity values during concentric phase and maximal strength training should be performed to provide an improvement in the movement velocity.

Structured Abstract: The common aim of many resistance training programs is that athletes can produce more strength with a certain absolute load or develop the conditional feature that will contribute to moving the same absolute load at higher velocity. In this context, determining the relation of load-velocity or load-power in an individual sense is one of the most commonly used parameters to evaluate muscle strength of the lower limbs (Cormie et al., 2010, Crewther et al., 2011, García-Ramos et al., 2016a). In terms of evaluating these parameters, loaded or unloaded squat jump movement is a common exercise to develop and test the lower body muscles (Samozino et al., 2008). The human body's ability to produce maximal strength is linked to the sporty success that results from a series of performances. Power - force - velocity relationships characterize the boundaries of the neuromuscular system to produce power. The production of the skeletal muscle and the maximum movement velocity are directly proportional to the force - velocity relationship. In a muscle contraction, the velocity of contraction is known to gradually reduce the force produced by the neuromuscular system. In this case, the mechanical power output is also defined as a product of force and velocity. So both force and velocity are very important components to reveal power (Cross et al., 2017).

The maximum strength defined as the highest strength produced by the neuromuscular system in a muscle or muscle group at the time of a maximal contraction without any time limitation is expressed as one repetition maximal (1TM) or $100 \%$ of the maximal, and shows the highest weight the athlete can lift in one go (Bompa et al., 2012). Anaerobic performance is the ability of an individual to perform maximal anaerobic exercise. The ability to produce the highest mechanical power in a few seconds (anaerobic power - peak power) and the ability to maintain high power efficiency in a very short time (anaerobic capacity-average power) are considered as the main indicators of anaerobic performance (Inbar and Chia, 2008). That is, the term anaerobic power and capacity is often used according to the consumption of two different anaerobic energy systems. Anaerobic power, as the ability of the individual to use the phosphogen system in very short and high intensity muscle activities; anaerobic capacity is defined as the total amount of energy produced from the combination of anaerobic glycolysis and phosphogen system (Kearney et al., 2000).

Thirty-six athletes studying at the Gumushane University, Physical Education and Sports Department, and holding an active athlete license in different sports branches voluntarily participated in this research. In the study, T-Force Dynamic Measurement System (Ergotech Consulting SL Murcia, Spain), a linear velocity transducer, was used to determine the velocity (MV: mean velocity, MPV: mean propulsive velocity, PV: peak velocity) values in the loaded squat jump motion. Since body weight is important in determining the external load to be used in the loaded squat jump movement, the body weights of all participants were detected before the test, and the loads corresponding to $40 \%$ of their own body weight for each participant were determined, and the external loads to be used during the squat jump for each athlete were recorded. To determine the maximal dynamic strength property of the subjects, one repetition maximal (1TM) strength test was performed using the procedure designed by Beachle et al., (2008) in full back squat movement. Wingate anaerobic power test (WanT) was carried out using a bicycle ergometer (Monark 839E Sweden) to measure the anaerobic power and capacity of the subjects. During the test, after the participants cycled without a load for a few seconds, when they reached the specified pedal speed, a load corresponding to $7.5 \%$ of each subject's body weight was applied as resistance and pedaled at high speed against the resistance created by this load for 30 seconds. Pedal counts were recorded for every 5 seconds and all power parameters were calculated with the computer software program as absolute and relative values. Shapiro-Wilk normality test, Descriptive Statistics, and Pearson Correlation were performed to evaluate the data. SPSS 16.0 (SPSS Inc, Chicago, IL) package program was used in all statistical calculations

According to the results of the analysis, although there was a statistically positive and low relationship between absolute 1RM full back squat strength and peak velocity parameter $(r=, 366 ; p<0.05)$, a positive and moderate level between the relative 1RM squat strength and peak velocity parameter relationship $(r=, 431 ; p$ $<0.01$ ) was obtained. There was a statistically positive and moderately significant correlation between absolute 1RM squat strength and absolute maximal anaerobic power $(\mathrm{r}=, 432)$ and absolute average anaerobic power $(\mathrm{r}=$, 462) ( $\mathrm{p}<0.01)$. Considering the relationship between anaerobic performance and velocity values, there was only a statistically positive and low level $(\mathrm{r}=, 354 ; \mathrm{p}<0.05)$ significant relationship between relative average anaerobic power and peak velocity values. Apart from these parameters, there was no statistically significant relationship ( $\mathrm{p}>0.05)$. 
This study is the first study to investigate whether anaerobic power and maximal strength are important factors for velocity values during loaded squat jump movement. Consequently, anaerobic power and maximal strength is an important factor affecting the movement velocity, an increase in the peak velocity values in the concentric phase will occur with the increase of muscle strength and anaerobic power. Therefore, it can be argued that maximal strength and explosive anaerobic power training should be performed to improve movement speed.

Keywords: Squat, Jumping, Velocity, Anaerobic Power, Strength

Öz: Bu çalışmanın amacı; ağırlıklı squat sıçrama hareketi esnasındaki hız değerleri için anaerobik güç ve maksimal kuvvetin önemli bir faktör olup olmadığının belirlenmesidir. Bu amaç doğrultusunda; Gümüşhane Üniversitesi Beden Eğitimi ve Spor Yüksekokulunda öğrenim gören ve farklı spor branşlarında aktif sporcu lisansına sahip olan 36 sporcu öğrenci (yaş: 21,4 $\pm 1,57$ yıl; boy: 175,2 \pm 5,91 cm; kilo: 68,7 $\pm 7,12 \mathrm{~kg}$ ) çalışmaya gönüllü olarak katıldı. Çalışmada, katılımcıların hız parametrelerini belirlemek için kendi vücut ağırlıklarının \% 40'ına karşılık gelen bir dış yük kullanılarak ağırlıklı squat sıçrama (SS Yük) hareketi yaptırıldı. Ayrıca, katılımcıların maksimal dinamik kuvvet özelliğini belirlemek için tam squat ( $\mathrm{SQ}_{\mathrm{Tam}}$ ) hareketinde bir tekrarlı maksimal (1TM) kuvvet testi ve anaerobik güç testi yaptırıldı. Verilerin analizi için Shapiro-Wilk normallik testi, tanımlayıcı istatistik ve Pearson korelasyon analizleri kullanıldı. Analiz sonuçlarına göre; katılımcıların relatif ortalama anaerobik güç ve $\mathrm{SQ}_{\mathrm{Tam}}$ hareketindeki absolut ve relatif 1TM kuvvet değeri ile $\mathrm{SS}_{\text {Yük }}$ hareketinin konsantrik evresinde elde edilen zirve hız değerleri arasında pozitif yönde istatistiksel olarak anlamlı bir ilişki olduğu elde edildi. Ayrıca, absolut 1TM squat kuvveti ile hem absolut maksimal anaerobik güç hem de absolut ortalama anaerobik güç değerleri arasında pozitif yönde istatistiksel olarak anlamlı bir ilişki olduğu elde edildi. Bunun dışında, istatistiksel olarak herhangi bir anlamlı ilişki elde edilmedi. Sonuç olarak hem absolut hem de relatif bakımdan kuvvet ve zirve hız değerleri arasında anlamlı ilişki olmasından dolayı, kuvvet özelliği arttığında konsantrik evre esnasındaki zirve hız değerlerinde bir artış meydana geleceği ve hareket hızında bir gelişme sağlamak için maksimal kuvvet antrenmanlarının yapılması gerektiği ileri sürülebilir.

Anahtar Kelimeler: Squat, Sıçrama, Hız, Anaerobik Güç, Kuvvet

\section{Giriş}

Birçok direnç antrenman programının ortak amacı, belli bir mutlak yükle bireyin daha fazla kuvvet üretebilmesi veya diğer bir ifadeyle aynı mutlak yükü daha yüksek hızda hareket ettirilmesine katk1 sağlayacak kondisyonel özelliğinin geliştirilmesidir. Bu bağlamda, bireysel anlamda yük - hız ya da yük - güç ilişkisinin belirlenmesi, alt ekstremite kas gücünün belirlenmesinde en sık kullanılan parametrelerden biridir (Cormie ve ark. 2010, Crewther ve ark., 2011, García-Ramos ve ark., 2016a). Bu parametrelerin belirlenmesi açısından ağırlıklı ya da ağırlıksız yapılan squat sıçrama hareketi, alt vücut kaslarını geliştirmek ve test etmek için yaygın olarak kullanılan bir harekettir. Bunun en önemli sebebi, vücudun dinlenme pozisyonunda iken hızlı bir şekilde hareket etme yeteneğinin birçok spor branşında başarıya etkisi olmasıdır (Samozino ve ark, 2008). Yapılan çalışmalarda, farklı dış yüklere karşı bireylerin kuvvet uygulama yeteneğini değerlendirme için squat sıçrama hareketinin yoğun bir şekilde kullanıldığı görülür (Garcia-Ramos ve ark., 2016b; Perez-Castilla ve ark., 2020).

Maksimal kas gücünü üretebilme yeteneği, bireyin güç seviyesinden önemli ölçüde etkilenir. Uzun vadeli güç gelişimi dikkate alındığında, maksimal gücü arttırma ve koruma oldukça önemlidir. $\mathrm{Bu}$ nedenle, ağır yüklerle uygulanan kuvvet antrenmanları, sporcuların antrenman programlarındaki önemli bir bileşen olarak kabul edilir. Antrenmanların performansa aktarımını maksimale çıkarmak için uygulanan güç çalışmalarında, bireylerin yaptıkları sporların taleplerine özgü hareket modelleri, yükler ve hizların kullanılması gerekir (Cormie ve ark., 2011).

İnsan vücudunun maksimal güç üretme yeteneği, bir dizi performans sonucunda ortaya çıkan sportif başarı ile bağlantılıdır. Güç - kuvvet - hız ilişkileri, güç üretmek için nöromüsküler sistemin sınırlarını karakterize eder (Cross ve ark., 2017). Bireysel kuvvet - hız (F-v) ve güç - hız ilişkileri ise genellikle bireyin mekanik yeteneklerini değerlendirmek için belirlenir. Bu temel motorik özellikler 
arasındaki ilişkiler, artan hareket hızı ile dış kuvvet üretimi ve güç çıkışındaki farklılıkları ifade eder. Maksimal kuvvet, maksimal güç çıkışı ve maksimal hız olmak üzere üç değişken sınıflandırabiliriz (Jimenez-Reyes ve ark. 2017). İskelet kasının kuvvet üretmesi ve maksimal hareket hızı kuvvet - hız ilişkisi ile doğru orantılıdır. Bir kas kasılmasında, kasılma hızının nöromüsküler sistem tarafından üretilen kuvveti kademeli olarak azalttı̆̆ı bilinir. Bu durumda, mekanik güç çıkışı da kuvvet ve hızın bir ürünü olarak tanımlanır. Dolayısıyla, hem kuvvet hem de hız, gücü ortaya çıkarmak için oldukça önemli bileşenlerdir (Cross ve ark., 2017).

Literatürde, üst vücut kuvvet özelliğinin yumruk - tekme savurma hızı (Loturco ve ark. 2014) ile hareket hızı (Can, 2018; Can ve Bayrakdaroğlu, 2019) arasındaki ilişkileri araştıran sınırlı sayıda çalışma bulunurken, hareket hızı ve anaerobik güç özelliği arasındaki mevcut ilişkileri araştıran bir çalışmaya rastlanılmamıştır. Sportif başarı için önemli bir faktör olduğu düşünülen hareket hızının, anaerobik güç ve kas kuvveti ile ilişkisinin belirlenerek hareket hızını geliştirmede kullanılabilecek yaklaşımları ortaya koyması bakımından önemli olacağı düşünülmektedir. Literatürde, bu kapsamda yapılan bir çalışmanın olmaması ve elde edilecek sonuçlar ile spor bilimleri literatüründeki bir açığı dolduracak olan bu çalışmanın amacı, ağırlıklı squat sıçrama hareketi esnasındaki hız değerleri için anaerobik güç ve maksimal kuvvetin önemli bir faktör olup olmadığının araştırılmasıdır.

\section{Yöntem}

\section{Katılımellar}

Bu çalışmaya, Gümüşhane Üniversitesi Beden Eğitimi ve Spor Yüksekokulunda öğrenim gören ve farklı spor branşlarında aktif sporcu lisansına sahip 36 sporcu öğrenci (yaş: 21,4 $\pm 1,57$ yıl; boy: $175,2 \pm 5,91 \mathrm{~cm}$; kilo: $68,7 \pm 7,12 \mathrm{~kg}$ ) gönüllü olarak katıldı. Araştırma öncesinde, tüm sporcular ve antrenörlerine araştırmanın amacı, çalışmada uygulanacak test prosedürleri ve karşılaşılabilecek potansiyel riskler ile araştırma sonunda ulaşılacak sonuçların ilgili spor branşları ve spor bilimlerine yararları hakkında detaylı bilgilendirmeler yapıldı ve katılımcılara çalışmaya gönüllü katıldıklarına dair yazılı bir onam belgesi imzalatıldı.

\section{Prosedürler}

\section{Ă̆ırlıklı Squat Sıçrama Testi}

$\mathrm{Bu}$ çalışmada, katılımcıların ağırlıklı squat sıçrama ( $\left.\mathrm{SS}_{\text {Yük}}\right)$ hareketindeki hız (OH:ortalama hız, OİH:ortalama itme hızı, ZH:zirve hız) değerlerini belirlemede doğrusal bir hız dönüştürücü olan T-Force Dinamik Ölçüm Sistemi (Ergotech Consulting SL Murcia, İspanya) kullanıldı. SS Yük hareketi için dış yükün belirlenmesinde katılımcıların kendi vücut ağırlıkları önemlidir. Bu nedenle, test öncesinde tüm katılımcıların vücut ağırlı̆̆ belirlenerek her katılımcının kendi vücut ağırlı̆̆ının \%40'a denk gelen yükler hesaplandı ve squat sıçraması esnasında kullanılacak dış yükler kaydedildi. Serbest ağırlıklar kullanılarak $\mathrm{SS}_{\text {Yük }}$ hareketi yaptırıldı. Testin uygulanışında, katılımcıların statik bir pozisyondan uylukları yere paralel olana kadar dizlerini fleksiyona getirmeleri ve başla komutundan sonra omuzları barla teması kaybetmeden mümkün olduğu kadar hızlı şekilde sıçramaları ve sıçrama hareketini 3 kez tekrar etmeleri istendi (Loturco ve ark. 2015). Akıcı bir ritimle yapılan bu üç sıçrama hareketindeki en yüksek hız değeri, istatistiksel analizler için kaydedildi. Hareketin uygulanmasında, kullanılan dış yüke ilaveten katılımcıların kendi ağırlığını da hareket ettirmesi ve toplam kütlelerini (dış yük ve vücut ağırlığı) ivmelendirme yetenekleri ile hız parametreleri belirleneceğinden dolayı, testin doğru yapılabilmesi için göz önüne alınması gereken gereklilikler eksik yapıldığında hareket katılımcılara tekrar yaptırıldı (Cormie ve ark., 2007).

\section{Maksimal Dinamik Kuvvet Testi}

Katılımcıların maksimal dinamik kuvvet özelliğini belirlemek için tam squat hareketinde bir tekrarlı maksimal (1TM) kuvvet testi yaptırıldı. 1TM kuvvet testi, Smith makinede (Esjim IT7001, Eskişehir, Türkiye) Beachle ve ark. (2008) tarafından tasarlanan prosedürle uygulandı. Bu yöntemde; 
1. Katılımcılara 20 dakika süren genel bir 1sınma yaptırıldı ve daha sonra katılımcıların 510 tekrar arası yapabilecekleri bir kaldırış yükü belirlenerek ısındırıldılar,

2. Toparlanmaları için bir (1) dakikalık bir süre verildi,

3. Katılımcıların birinci basamakta kullandığı kaldırış yüküne $14-18 \mathrm{~kg}$ arasında bir yük ilave edilerek 3-5 tekrar yapabilecekleri bir ısınma yükü belirlendi,

4. Toparlanmaları için iki (2) dakikalık bir süre verildi,

5. Katılımcıların üçüncü basamakta kullandığı kaldırış yüküne 14-18 kg arasında bir yük ilave edilerek 2-3 tekrar yapabilecekleri bir ısınma yükü belirlendi,

6. Toparlanmaları için üç (3) dakikalık bir süre verildi,

7. Katılımcıların beşinci basamakta kullandığ 1 kaldırış yüküne 14-18 kg arasında bir yük ilave edilerek 1TM girişimi yaptırıldı,

8. Toparlanmaları için üç (3) dakikalık bir süre verildi,

9. Katılımcılar yedinci basamaktaki dış yükü kaldırmada başarılı olursa yük aynı oranlar kullanılarak artırıldı. Fakat 1TM denemesinde başarısız olurlarsa 7-9 kg arasında yük azaltılarak ağırlık kaldırıldı,

10.Toparlanmaları için üç (3) dakikalık bir süre verildi,

11. Katılımcılar uygun bir teknikle 1TM testini tamamlayana kadar yük azaltılıp artırıldı ve katılımcılarının 1TM değerine maksimal 5 girişimde ulaşıldı.

Tam squat ( $\mathrm{SQ}_{\mathrm{Tam}}$ ) hareketinin yapılmasında, Earle ve Beachle (2008) tarafindan tasarlanan prosedür kuralları dikkate alındı. Bu prosedüre göre katılımcıların ayakları omuz genişliğinden biraz daha açık olacak bir pozisyonda ağırlık barını kavrayarak omuzlarına yerleştirmeleri ve uyluklar yere paralel olana kadar alçalarak daha sonra herhangi bir dış destek (yardımcısız) olmadan ağırlık barını hızlı bir şekilde kaldırmaları gerekmektedir. Katılımcıların güvenliğini sağlamak için ağırlık barının her iki yanına birer yardımcı yerleştirildi. Kaldırışlardaki performansı artırabilmek için katılımcılara güçlü sözel cesaretlendirmeler verildi.

\section{Anaerobik Güç Testi}

Katılımcıların anaerobik güç ve kapasitesini belirlemek için bisiklet ergometresinde (Monark 839E Sweden) Wingate anaerobik güç testi (WanT) yaptırıldı. Test öncesinde, tüm katılımcılara test prosedürüne alışmaları için 5 dakikalık ısınma çalışması uygulandı. Test sırasında katılımcılar birkaç saniye yüksüz olarak pedal çevirdikten sonra, belirlenen pedal hızına ulaştıklarında her deneğin vücut ağırlığının \%7.5'na denk gelen yük direnç olarak uygulandı ve 30 saniye süresince bu yük tarafından yaratılan dirence karşı yüksek hızda pedal çevirdiler. Her 5 saniye için pedal sayısı kaydedildi ve güç parametreleri absolut ve relatif değer olarak bilgisayar yazılım programı ile hesaplandı (Chia, 2000; Barfield ve ark., 2002; Chia ve Armstrong, 2007; Plowman ve Smith, 2008; Inbar ve Chia, 2008).

\section{İstatistiksel Analiz}

Verilerin değerlendirilmesi için shapiro-wilk normallik testi, tanımlayıcı istatistikler ve pearson korelasyon analizi yapıldı. Tüm istatistiksel hesaplamalar için SPSS 16.0 (SPSS Inc, Chicago, IL) paket programı kullanıldı.

\section{Bulgular}

Katılımcıların fiziksel ve performans özelliklerine yönelik tanımlayıcı analiz sonuçları (tablo 1), maksimal kuvvet ile hız parametreleri (tablo 2) ve anaerobik değerleri (tablo 3) arasındaki ilişki, hız parametreleri ve anaerobik değerler (tablo 4) arasındaki ilişki aşağıdaki tablolarda verilmiştir. 
Tablo 1: Katılımcıların Fiziksel ve Performans Özellikleri

\begin{tabular}{lcccc}
\hline Değişkenler & n & Minimum & Maksimum & Ortalama (ss) \\
\hline Yaş (kg) & 36 & 19,0 & 27,0 & $21,4( \pm 1,57)$ \\
Boy (cm) & 36 & 162,0 & 186,0 & $175,2( \pm 5,91)$ \\
Kilo (kg) & 36 & 54,2 & 85,0 & $68,7( \pm 7,12)$ \\
Absolut 1TM Squat Kuvveti (kg) & 36 & 100,0 & 155,0 & $120,1( \pm 13,4)$ \\
Relatif 1TM Squat Kuvveti & 36 & 1,50 & 2,09 & $1,75( \pm, 16)$ \\
Ortalama Hız (m/sn) & 36 & 1,18 & 1,66 & $1,39( \pm, 11)$ \\
Ortalama İtme Hizı (m/sn) & 36 & 1,23 & 1,92 & $1,54( \pm, 15)$ \\
Zirve Hiz (m/sn) & 36 & 2,05 & 2,94 & $2,42( \pm, 21)$ \\
Absolut Maksimal Anaerobik Güç (W) & 36 & 544,8 & 1101,6 & $798,0( \pm 119,3)$ \\
Relatif Maksimal Anaerobik Güç (W/kg) & 36 & 8,32 & 14,95 & $11,5( \pm 1,44)$ \\
Absolut Ortalama Anaerobik Güç (W) & 36 & 374,5 & 710,4 & $540,7( \pm 69,7)$ \\
Relatif Ortalama Anaerobik Güç (W/kg) & 36 & 6,54 & 9,62 & $7,80( \pm, 59)$ \\
\hline
\end{tabular}

Tablo 2: Maksimal Dinamik Kuvvet ve Hız Parametreleri Arasındaki İlişki

\begin{tabular}{llccc}
\hline & & OH & OİH & ZH \\
\hline Absolut 1TM Squat Kuvveti & Pearson Correlation &, 226 &, 238 &, $366^{*}$ \\
& Sig. (2-tailed) &, 186 &, 163 &, 028 \\
& $\mathrm{~N}$ & 36 & 36 & 36 \\
\cline { 2 - 5 } Relatif 1TM Squat Kuvveti & Pearson Correlation &, 262 &, 233 &, $431^{* *}$ \\
& Sig. (2-tailed) &, 123 &, 172 &, 009 \\
& $\mathrm{~N}$ & 36 & 36 & 36 \\
\hline
\end{tabular}

OH: Ortalama Hız; OİH: Ortalama İtme Hızı; ZH: Zirve Hız

Absolut 1TM tam squat kuvveti ile zirve hız parametresi arasında istatistiksel olarak pozitif yönde ve düşük bir ilişki olmasına rağmen $(\mathrm{r}=, 366$; $\mathrm{p}<0.05)$, relatif 1TM squat kuvveti ile zirve hız parametresi arasında pozitif yönde ve orta düzeyde bir ilişki $(r=, 431 ; \mathrm{p}<0.01)$ vardır (Tablo 2).

Tablo 3: Maksimal Dinamik Kuvvet ve Anaerobik Performans Arasındaki İlişki

\begin{tabular}{llcccc}
\cline { 3 - 6 } Absolut 1TM Squat Kuvveti & MAG $_{\text {Absolut }}$ & MAG $_{\text {Relatif }}$ & OAG $_{\text {Absolut }}$ & OAG $_{\text {Relatif }}$ \\
& Pearson Correlation &, $432^{* * *}$ &, 076 &, $462^{* * *}$ &, 101 \\
& Sig. (2-tailed) &, 009 &, 661 &, 005 &, 559 \\
& $\mathrm{~N}$ & 36 & 36 & 36 & 36 \\
\cline { 2 - 6 } Relatif 1TM Squat Kuvveti & Pearson Correlation &,- 090 &, 247 &,- 234 &, 190 \\
& Sig. (2-tailed) &, 603 &, 146 &, 170 &, 267 \\
& $\mathrm{~N}$ & 36 & 36 & 36 & 36 \\
\hline
\end{tabular}

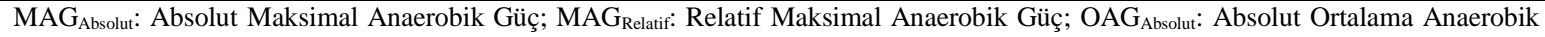



Absolut 1TM squat kuvveti ile hem absolut maksimal anaerobik güç ( $\mathrm{r}=, 432)$ hem de absolut ortalama anaerobik güç $(\mathrm{r}=, 462)$ değerleri arasında istatistiksel olarak pozitif yönde ve orta düzeyde anlamlı bir ilişki vardır ( $\mathrm{p}<0.01$; Tablo 3$)$. 
Tablo 4: Anaerobik Performans ve Hız Parametreleri Arasındaki İlişki

\begin{tabular}{clccc}
\cline { 3 - 4 } & & OH & OİH & ZH \\
\hline \multirow{3}{*}{ MAG $_{\text {Absolut }}$} & Pearson Correlation &, 140 &, 177 &, 270 \\
& Sig. (2-tailed) &, 415 &, 301 &, 112 \\
& $\mathrm{~N}$ & 36 & 36 & 36 \\
\cline { 2 - 5 } Pearson Correlation $_{\text {Relatif }}$ &, 263 &, 231 &, 255 \\
& Sig. (2-tailed) &, 121 &, 175 &, 134 \\
& $\mathrm{~N}$ & 36 & 36 & 36 \\
\hline \multirow{3}{*}{$\mathrm{OAG}_{\text {Absolut }}$} & Pearson Correlation &, 098 &, 167 &, 278 \\
& Sig. (2-tailed) &, 569 &, 331 &, 100 \\
& $\mathrm{~N}$ & 36 & 36 & 36 \\
\hline \multirow{2}{*}{$\mathrm{OAG}_{\text {Relatif }}$} & Pearson Correlation &, 323 &, 314 &, 354 \\
& Sig. (2-tailed) &, 055 &, 062 &, 034 \\
& $\mathrm{~N}$ & 36 & 36 & 36 \\
\hline
\end{tabular}





Anaerobik performans ve hız değerleri arasındaki mevcut ilişki incelendiğinde, sadece relatif ortalama anaerobik güç ve zirve hız değerleri arasında istatistiksel olarak pozitif ve düşük düzeyde $(\mathrm{r}=, 354 ; \mathrm{p}<0.05)$ anlamlı bir ilişki vardır. Bu parametreler haricinde istatistiksel olarak anlamlı ilişki yoktur ( $\mathrm{p}>0.05$; Tablo 4$)$.

\section{Tartışma ve Sonuç}

Sportif faaliyetler ve diğer fiziksel aktivitelerde maksimal efor gösterilmesine katk1 sağlayan önemli yetenekleri belirlemede kullanılan güç ve kuvvet özellikleri (Harman, 2008), yüksek çalışma (iş) oranı (güç) ve büyük dirençlere (kuvvet) karşı çok yüksek bir kuvvet ortaya koyma yeteneğinin gerekli olduğu spor branşlarında çok önemlidir. Bu nedenle, birçok spor branşında kazanılan sportif başarı çoğunlukla sporcunun patlayıcı bacak gücü ve maksimal kuvvet özelliğine bağlıdır (Yessin ve Hatfield, 2007). Her vücut bölümü hareketinde çeşitli kasların kombinasyonu gerekir ve her bir kas karakteristik bir maksimal kuvvet sağlayabilir. Fakat kaslar, boyları kısalırken kendisine uygulanan dirençlere karşılık verebilecek karşı kuvveti ayarlayabilen bir özelliğe sahiptir. Kasın bu özelliği, kas kasılma sisteminin yarattı̆̆ hızın karşı dirençlere göre sürekli ayarlanmasına dayanır (Edman ve ark., 1978). Yani dış direnç (yük) arttıkça, kas tarafindan üretilen kuvvet değeri artmasına rağmen hareket hızında azalma olmasıdır (Boreham, 2006). Vektörel bir nicelik olarak kabul edilen hız, pozisyonda meydana gelen değişimlerin zamansal oranı olarak tanımlanır (Zatsiorsky, 1998).

Bir zaman sınırlaması olmadan, maksimal bir kasılma anında sinir-kas sisteminin bir kas ya da kas grubunda ürettiği en yüksek kuvvet miktarı olarak tanımlanan maksimal kuvvet için literatürde bir tekrarlı maksimal (1TM) ya da maksimalin \%100'ü ifadeleri de kullanılır ve bireyin tek seferde kaldırabildiği en yüksek ağırlığı gösterir (Bompa ve ark., 2012). Maksimal kuvvetin submaksimal yüke karşı yapılan görev (iş) esnasında güç verimini belirleyen önemli faktörlerden biri olduğu ileri sürülür (Moss ve ark., 1997; Stone ve ark., 2003).

Bu çalışmada, absolut 1TM squat kuvveti ile zirve hız parametresi arasında pozitif yönde ve düşük bir ilişki olmasına rağmen, relatif 1TM squat kuvveti ile zirve hız parametresi arasında pozitif yönde ve orta düzeyde bir ilişki olduğu elde edildi. Literatürde, $\mathrm{SS}_{\text {Yük }}$ hareketindeki hız değeri ve alt vücut maksimal kuvvet değeri arasında ilişkinin araştırıldığı bir çalışma mevcut olmamasına rağmen, sadece farklı spor dallarındaki sporcuların üst vücut kuvvet özelliği ve hareket hızlarına yönelik bazı çalışmalar mevcuttur. Can (2018) tarafindan yapılan çalışmada, Türkiye 1. Hentbol liginde mücadele 
eden ve en az 5 yıllık spor geçmişine sahip hentbol oyuncularının üst vücut kuvvet özelliği ve hareket hızları arasındaki ilişki araştııılmış ve katılımcıların bench press hareketindeki bir tekrarlı maksimal kuvvet değerleri ile bench throw (BT) hareketinde ulaşılan ortalama itme hızı $(\mathrm{r}=, 728)$ ve zirve hız $(\mathrm{r}=, 775)$ değerleri arasında pozitif, yüksek düzeyde ve istatistiksel olarak anlamlı bir ilişki olduğu elde edilmiştir ( $\mathrm{p}<0.01)$. Benzer şekilde, Can ve Bayrakdaroğlu (2019) tarafindan yapılan çalışmada, Avrupa ve Dünya şampiyonalarına katılan ve derece yapan boksör ve kickbokscuların bench press hareketindeki absolut 1TM değerleri ile BT hareketinin itme evresindeki ortalama itme hızı $(r=, 613)$ ve zirve hız $(r=, 641)$ değerleri arasında istatistiksel olarak anlamlı bir ilişkinin olduğu, buna karşıllk relatif 1TM bakımından bir ilişkinin olmadığ 1 belirlenmiştir. Loturco ve ark., (2014), Brezilya milli karate takımında yer alan sporcuların hem üst hem de alt vücut için vuruş hızları ile kuvvet değerleri arasında istatistiksel olarak anlamlı bir ilişki olduğunu bulmuşlardır.

Bir bireyin maksimal anaerobik egzersizi yapabilme yeteneği olarak tanımlanan anaerobik performansın, birkaç saniyede en yüksek mekaniksel gücü üretebilme (anaerobik güç - zirve güç) ve çok kısa zaman diliminde yüksek güç verimini sürdürebilme yeteneği (anaerobik kapasite - ortalama güç) olarak iki temel göstergesi olduğu düşünülür (Inbar ve Chia, 2008). Yani, anaerobik kapasite ve güç terimi genellikle iki farklı anaerobik enerji sisteminin tüketimine göre kullanılır. Çok kısa süreli ve yüksek şiddetli kas aktivitelerinde bireyin fosfojen sistemini kullanabilme yeteneği anaerobik güç olarak tanımlanırken; anaerobik kapasite ise anaerobik glikoliz ve fosfojen sisteminin birleşiminden üretilen toplam enerji miktarı olarak tanımlanır (Kearney ve ark., 2000). Kas kuvveti özelliğinin anaerobik performans yeteneğini etkileyen bir kriter olduğu ifade edilir (Young ve ark., 1995). Baker ve Nance (1999), anaerobik performans özelliğinin \%62'sini kuvvet performansı ile ilişkili olduğunu belirtmişlerdir.

Yapılan çalışmada, maksimal kuvvet ile maksimal anaerobik güç ve ortalama anaerobik güç değerleri arasında istatistiksel olarak pozitif ve orta düzeyde anlamlı bir ilişki olduğu elde edildi. Bu bulgular, daha önceleri farklı yöntem ve katılımcı gruplarında tamamlanan çalışmalarda elde edilen sonuçlar ile paralellik göstermektedir. Literatüre bakıldığında, Özkan ve ark (2009) tarafindan kuvvet ve anaerobik performans arasındaki ilişkinin araştırılması için Amerikan futbolcularında yapılan bir çalışmada, maksimal anaerobik güç değerleri ile $60^{\circ} / \mathrm{s}^{-1}, 150 \% \mathrm{~s}^{-1}$ ve $240^{\circ} / \mathrm{s}^{-1}$ diz ekstansiyon kuvveti ile $240^{\circ} / \mathrm{s}^{-1}$ diz fleksiyon kuvveti arasında; ortalama anaerobik güç değerleri ile $60^{\circ} / \mathrm{s}^{-1}, 150^{\circ} / \mathrm{s}^{-1}$ ve $240 \% \mathrm{~s}^{-1}$ diz ekstansiyon kuvveti ile $60^{\circ} / \mathrm{s}^{-1}$ diz fleksiyon kuvveti arasında istatistiksel olarak anlaml bir ilişsi olduğu bulunmuştur. Kin-İşsler ve ark., (2008) tarafindan Amerikan futbolcularında yapılan bir çalışmada, farklı kasılma hızlarında $\left(60^{\circ} / \mathrm{s}^{-1}, 150^{\circ} / \mathrm{s}^{-1}, 240^{\circ} / \mathrm{s}^{-1}\right)$ uygulanan izokinetik diz ekstansör kuvveti ile anaerobik güç ve kapasite arasında anlamlı bir ilişki olduğu elde edilmiş̧ir. Alemdaroğlu (2012), basketbolcuların sağ - sol ayak $60^{\circ} / \mathrm{s}^{-1}$ ve $180^{\circ} / \mathrm{s}^{-1}$ izokinetik diz ekstansör kas kuvveti ve zirve güç değeri arasında istatistiksel olarak anlamlı bir ilişki elde etmiştir. Thorland ve ark. (1987) ise elit genç kadın sprint ve orta mesafe koşucularında yaptıkları bir çalışmada, katılımcıların $30^{\circ} / \mathrm{s}^{-1}, 60^{\circ} / \mathrm{s}^{-}$ ${ }^{1}, 120^{\circ} / \mathrm{s}^{-1}, 180^{\circ} / \mathrm{s}^{-1}, 240^{\circ} / \mathrm{s}^{-1}$ ve $300^{\circ} / \mathrm{s}^{-1}$ izokinetik diz ekstansör kuvvet değeri ile hem anaerobik güç hem de anaerobik kapasite değerleri arasında istatistiksel olarak yüksek düzeyde, pozitif ve anlamlı bir ilişki olduğunu elde etmişlerdir.

Zorba ve ark., (2010) tarafından güreşçilerde yapılan bir çalışmada, izometrik bacak kuvveti ile maksimal anaerobik güç değerleri arasında orta düzeyde bir ilişki olduğu; ortalama anaerobik güç değerleri arasında ise istatistiksel olarak yüksek düzeyde, pozitif ve istatistiksel olarak anlamlı bir ilişki olduğu bulunmuştur. Benzer şekilde, Özkan ve Sarol (2008) tarafından dağcılarda tamamlanan çalışmada, izometrik bacak kuvveti ile maksimal anaerobik güç ve ortalama anaerobik güç değerleri arasında yüksek düzeyde, pozitif ve istatistiksel olarak anlamlı bir ilişki olduğu bulunmuştur. Arslan (2005) tarafından sağlıklı bireylerde yapılan bir çalışmada ise izometrik bacak kuvveti ve anaerobik performans arasında istatistiksel olarak anlamlı bir ilişki olduğu elde edilmiştir. 
Ağırlıklı squat sıçrama hareketinin konsantrik evresi esnasındaki hız değerleri için anaerobik güç ve maksimal kuvvetin önemli bir faktör olup olmadığının araştırılması bakımından spor bilimleri literatüründe ilk olma özelliği taşıyan bu araştırmada ulaşılan sonuçların önemli olduğu düşünülür. $\mathrm{Bu}$ çalışmada, zirve hız parametresi ile relatif ortalama anaerobik güç ve hem absolut hem de relatif 1TM squat kuvveti arasında istatistiksel olarak pozitif yönde ve anlamlı bir ilişki olduğu elde edildi. Sonuç olarak, anaerobik güç ve maksimal kuvvetin hareket hızını etkileyen önemli bir faktör olduğu, kas kuvveti ve anaerobik gücün artması ile konsantrik evredeki zirve hız değerlerinde bir artış olacağı ve bu nedenle hareket hızında gelişme sağlamak için maksimal kuvvet ve patlayıcı tarzda anaerobik güç antrenmanlarının yapılması gerektiği ileri sürülebilir.

\section{Kaynakça}

Alemdaroğlu, U. (2012). The relationship between muscle strength, anaerobic performance, agility, sprint ability and vertical jump performance in professional basketball players. Jounal of Human Kinetic, 31(1), 149-158. https://doi.org/10.2478/v10078-012-0016-6

Arslan, C. (2005). Relationship between the 30-second wingate test and characteristics of isometric and explosive leg strength in young subjects. Journal of Strength and Conditioning Research, 19(3), 658-666. https://doi.org/10.1519/14533.1

Baker, D., Nance, S. (1993). The relation between strength and power in professional rugby league players. Journal of Strength and Conditioning Research, 13(3), 224-229. https://doi.org/10.1519/1533-4287(2001)015<0030:COUBSA>2.0.CO;2

Barfield, JP., Sells, PD., Rowe, DA., Downs, KH. (2002). Practice effect of the wingate anaerobic test. Journal of Strength and Conditioning Research, 16(3), 472-473. https://doi.org/10.1519/1533-4287(2002)016<0472:PEOTWA>2.0.CO;2

Beachle, TR., Earle, RW., Wathen, D. (2008). Resistance training. In Beachle, TR., Earle, RW (Ed). Essentials of strength training and conditioning ( $3^{\text {rd }}$ edition) (pp. 381-412). Champaign, IL: Human Kinetics.

Bompa, OT., Di-Pasquale, M., Cornacchia, L. (2012). Serious strength training. United States: Human Kinetics, 259-270.

Boreham, C. (2006). The physiology of sprint and power training. Whyte, G. (Ed.). The physiology of training: Advances in sport and exercise science Series. Philadelphia: Churchill Livingstone Elsevier.

Can, I. (2018). Analysis on relation between velocity and power values during propulsive phase of bench throw exercise and upper body strength characteristics in handball players. European Journal of Phyical Education and Sport Science, 4(1), 10-27. http://dx.doi.org/10.5281/zenodo.1112458

Can, I., Bayrakdaroğlu, S. (2019). Türk milli boksör ve kickbokscularda üst vücut kuvvet özelliği ve bench throw hareketi esnasındaki bazı parametrelerin karşılaştırılması. CBÜ Beden Ĕgitimi ve Spor Bilimleri Dergisi, 14(1), 121-128. https://doi.org/10.33459/cbubesbd.548462

Chia, M. (2000). Assessing young people's exercise using anaerobic performance tests. European Journal of Physical Education, 5(2), 231-258. https://doi.org/10.1080/1740898000050209

Chia, M., Armstrong, N. (2007), Maximal intensity exercise, (Ed: Armstrong, N.), Pediatric exercise physiology, China, Churchill Livingstone Elsevier. 
Cormie, P., McCaulley, GO., Triplett, NT., McBride, JM. (2007). Optimal loadig for maximal power output during lower body resistance exercises. Medicine and Science in Sports and Exercise, 39(2), 340-349. https://doi.org/10.1249/01.mss.0000246993.71599.bf

Cormie, P., McGuigan, MR., Newton, RU. (2010). Adaptations in athletic performance after ballistic power versus strength training. Medicine and Science in Sports and Exercise, 42(8), 15821598. https://doi.org/10.1249/MSS.0b013e3181d2013a

Cormie, P., McGuigan, MR., Newton, RU. (2011). Developing maximal neuromuscular power: Part 2 - training considerations for improving maximal power production. Sports medicine, 41(2), 125-146. https://doi.org/10.2165/11538500-000000000-00000

Crewther, BT., Kilduff, LP., Cunningham, DJ., Cook, C., Owen, N., Yang, GZ. (2011). Validating two systems for estimating force and power. International Journal of Sports Medicine, 32(4), 254-258. https://doi.org/10.1055/s-0030-1270487

Cross, MR., Brughelli, M., Samozino, P., Morin, JB. (2017). Methods of power-force-velocity profiling during sprint running: a narrative review. Sports Medicine, 47(7), 1255-1269. https://doi.org/ 10.1007/s40279-016-0653-3.

Earle, RW., Beachle, TR. (2008). Resistance training and spotting techniques. In Beachle, TR., Earle, RW. (Ed). Essentials of strength training and conditioning ( $3^{\text {rd }}$ edition) (pp. 325-376). Champaign, IL: Human Kinetic.

Edman, KAP., Elzinga, G., Noble, MIM. (1978). Enhancement of mechanical performance by stretch during tetanic contractions of vertebrate skeletal muscle fibres. The Journal of Physiology, 281, 139-155. https://doi.org/ 10.1113/jphysiol.1978.sp012413

García-Ramos, A., Stirn, I., Strojnik, V., Padial, P., De la Fuente, B., Argüelles-Cienfuegos, J., Feriche, B. (2016a). Comparison of the force-, velocity-, and power-time curves recorded with a force plate and a linear velocity transducer. Sports Biomechanics, 15(3), 329-341. https://doi.org/ 10.1080/14763141.2016.1161821

García-Ramos, A., Štirn, I., Padial, P., Argüelles-Cienfuegos, J., De la Fuente, B., Calderon, C., Feriche, B. (2016b). The effect of an altitude training camp on swimming start time and loaded squat jump performance. PloS One, 11(7), 1-11. https://doi.org/10.1371/journal.pone.0160401

Harman, E. (2008). Biomechanics of resistance exercise. Beachle, TR., Earle, WR. (Ed.). Essentials of strength training and conditioning ( $3^{\text {rd }}$ Edition). Champaign, IL: Human Kinetics.

Inbar, O., Chia, M. (2008). Development of maximal anaerobic performance an old issue revisited, (Ed. Hebestreit, H., Bar-Or, O.), The young athlete $\left(1^{\text {th }}\right.$ ed.), Singapore, Blackwell Publishing.

Jimenez-Reyes, P., Samozino, P., Pareja-Blanco, F., Conceiçao, F., Cuadrado-Penafiel, V., Gonzalez-Badillo, J.J., Morin, J.B. (2017). Validity of a simple method for measuring forcevelocity-power profile in countermovement jump. International journal of sports physiology and performance, 12(1), 36-43. https://doi.org/ 10.1123/ijspp.2015-0484

Kearney, JT., Rundell, KW., Wilber, RL. (2000). Measurement of work and power in sport, (Ed. Garrett, W.E, Kirkendall, TD.), Exercise and sport science, Philadelphia, Lippincott Williams \& Wilkins.

Kin-İşler, A, Arıburun, B., Ozkana, A., Aytarb, A., Tandogan, R. (2008). The relationship between anaerobic performance, muscle strength and sprint ability in American football players. Isokinetics and Exercise Science, 16(2), 87-92. https://doi.org/ 10.3233/IES-2008-0301 
Loturco, I., Artioli, GG., Kobal, R., Gil, S., Franchini, E. (2014). Predicting punching acceleration from selected strength and power variables in elite karate athletes: A multiple regression analysis. Journal of Strength and Conditioning Research, 28(7), 1826-1832. https:/doi.org/ 10.1519/JSC.0000000000000329

Loturco, I., D’Angelo, RA., Fernandes, V., Gil, S., Kobal, R., Cal Abad, CC., Kitamura, K., Nakamura, FY. (2015). Relationship between sprint ability and loaded / unloaded jump tests in elite sprinters. Journal of Strength and Conditioning Research, 29(3), 758-764. https://doi.org/ 10.1519/JSC.0000000000000660

Moss, BM., Refsnes, PE., Abildgaard, A., Nicolaysen, K., Jensen, J. (1997). Effects of maximal effort strength training with different loads on dynamic strength, cross-sectional area, loadpower and load-velocity relationships. European Journal of Applied Physiology and Occupational Physiology, 75(3), 193-199. https://doi.org/ 10.1007/s004210050147

Özkan, A., Sarol, H. (2008). Dağc1larda vücut kompozisyonu, bacak hacmi, bacak kütlesi, anaerobik performans ve bacak kuvveti arasındaki ilişki. Spormetre Beden Ĕgitimi ve Spor Bilimleri Dergisi, 6(4), 175-181. https://doi.org/ 10.1501/Sporm_0000000108

Özkan, A., Arıburun, B., Kin-İşler, A. (2009). Amerikan futbolu oyuncularında vücut kompozisyonu, izokinetik bacak kuvveti ve anaerobik performans arasındaki ilişki. Türkiye Klinikleri Journal of Sports Science, 1(1), 47-52.

Perez-Castilla, A., McMahon, JJ., Comfort, P., García-Ramos, A. (2020). Assessment of loaded squat jump height with a free-weight barbell and Smith machine: comparison of the takeoff velocity and flight time procedures. The Journal of Strength and Conditioning Research, 34(3), 671-677. https://doi.org/ 10.1519/JSC.0000000000002166

Plowman, AS., Smith, LD. (2008). Exercise physiology: For health, fitness and performance (2 ${ }^{\text {nd }}$ Ed.). Philadelphia, Lippincott Williams / Wilkins.

Samozino, P., Morin, JB., Hintzy, F., Belli, A.(2008). A simple method for measuring force, velocity and power output during squat jump. Journal of Biomechanic, 41(14), 2940-2945. https://doi.org/ 10.1016/j.jbiomech.2008.07.028

Stone, MH., Sanborn, K., O'Bryant, HS., Hartman, M., Stone, ME., Proulx, C., Ward, B., Hruby, J. (2003). Maximum strength-power performance relationships in college throwers. Journal of Strength and Conditioning Research, 17(4), 739-745. https://doi.org/ 10.1519/15334287(2003)017<0739:msrict>2.0.co;2

Thorland, WG. (1987). Strength and anaerobic responses of elite young female sprint and distance runners. Medicine Sciences and Sports Exercise, 19(1), 56-61.

Young, W., Mclean, B., Ardagna, J. (1995). Relationship between strength qualities and sprinting performance. Journal of Sports and Medicine Physical Fitness, 35(1), 13-9

Yessin, M., Hatfield, F. (2007). Plyometric training: Achieving explosive power in sports. ( ${ }^{\text {rd }}$ Ed.). Champaign, IL: Human Kinetics.

Zatsiorsky, VM. (1998). Kinematics of human motion. Champaign, IL: Human Kinetics.

Zorba, E., Özkan, A., Akyüz, M., Harmanc1, H., Taş, M., Şenel, Ö. (2010). Güreşçilerde bacak hacmi, bacak kütlesi, anaerobik performans ve bacak kuvveti arasındaki ilişki. International Journal of Human Sciences, 7(1), 83-96. 